\title{
Analyzing the Multiple Dimensions of Negotiation Processes
}

\author{
Michael Filzmoser ${ }^{1} \cdot$ Patrick Hippmann $^{2}$. \\ Rudolf Vetschera ${ }^{2}$
}

(C) The Author(s) 2016. This article is published with open access at Springerlink.com

\begin{abstract}
Negotiation processes involve a substantive, a communication, and an emotional dimension. These dimensions have been analyzed mainly in isolation of each other. We introduce an approach to consider all three dimensions and present an empirical study on the relations between these dimensions. Results indicate a strong linkage between communication behavior and emotions, while connections to the substantive dimension of the negotiation process are weaker.
\end{abstract}

Keywords Negotiation $\cdot$ Process $\cdot$ Utility $\cdot$ Communication $\cdot$ Emotions

\section{Introduction}

Negotiations can be analyzed from many different perspectives (Koeszegi and Vetschera 2010; Vetschera 2013). Over the last decades, two main streams of research on negotiations have emerged. One is mainly concerned with the substantive side of

A previous version of this paper was presented at the Joint International Conference of the INFORMS GDN Section and the EURO Working Group on DSS on Group Decision and Negotiation 2014, Toulouse, France (Filzmoser et al. 2014).

$凶 \quad$ Rudolf Vetschera

rudolf.vetschera@univie.ac.at

Michael Filzmoser

michael.filzmoser@tuwien.ac.at

Patrick Hippmann

patrick.hippmann@univie.ac.at

1 Institute of Management Science, Vienna University of Technology, Wien, Austria

2 Department of Business Administration, University of Vienna, Wien, Austria 
negotiations. This stream can be exemplified by the concept of negotiation analysis (Raiffa 1982; Sebenius 1992). It views a negotiation mainly as a sequence of offers and counteroffers and is predominantly concerned with economic criteria like efficiency and utilities of parties.

In parallel, a more behaviorally oriented stream has emerged, which emphasizes the role of communication in negotiations (Holmes 1992). Researchers in this domain have developed classification schemes for communication acts (Olekalns et al. 2003) and phase models of negotiations (Adair and Brett 2005), which explain how communication content changes over time and influences the outcomes of negotiations. The main outcome considered in this stream is whether a negotiation reaches an agreement at all.

More recently, researchers have begun to consider emotions as yet another dimension of negotiations (Bazerman et al. 2000; Butt et al. 2005; Griessmair and Koeszegi 2009). This research has uncovered different emotional patterns in negotiations and thus has contributed to our understanding how emotions shape processes and outcomes of negotiations.

However, the relations between these three dimensions have only rarely been studied. With few exceptions (e.g., Overbeck et al. 2010), the emotional dimension so far has been studied mostly in isolation. Analyses of the substantive dimension often ignore the content of communication other than offers. Studies that focus on communication consider emotional or substantive content similarly to any other type of content. Emotions are represented by broad categories like "affective persuasion" (Adair and Brett 2005), substantive offers are sometimes distinguished and classified into "singleissue offer", "multi-issue offer" (Adair and Brett 2005; Olekalns and Smith 2003), or "concession" (Olekalns et al. 2003; Olekalns and Smith 2003), but without considering actual values.

In the present paper, we propose to analyze negotiation processes in the unified framework illustrated in Fig. 1. We view negotiation processes as three parallel streams, which evolve over time. The main focus of the present paper is on the relationship between these dimensions.

Since we are trying to integrate dimensions, which so far were analyzed in quite different streams of literature, our work is necessarily explorative. There are not many established theories that allow us to formulate hypotheses about the relationships between dimensions based on strong theory that covers all three dimensions of the negotiation process. To study such relationships, one needs to identify a "common ground" in the theoretical and empirical work dealing with these dimensions. Such a common ground could be found either in the outcomes of negotiations, or in negotiation processes.

Research on all three dimensions is concerned with their effects on outcomes, and one can identify effects which lead to similar outcomes. For example, concessions at the substantive level (Carnevale and Pruitt 1992), communication aimed at creating value (Olekalns and Smith 2000), and positive emotions (Brett et al. 2007) all have positive effects on reaching an agreement. However, it would be far-fetched to assume that behavior leading to similar outcomes necessarily occurs together. Whether actions at the different dimensions are substitutes or complements, and how consistency across 


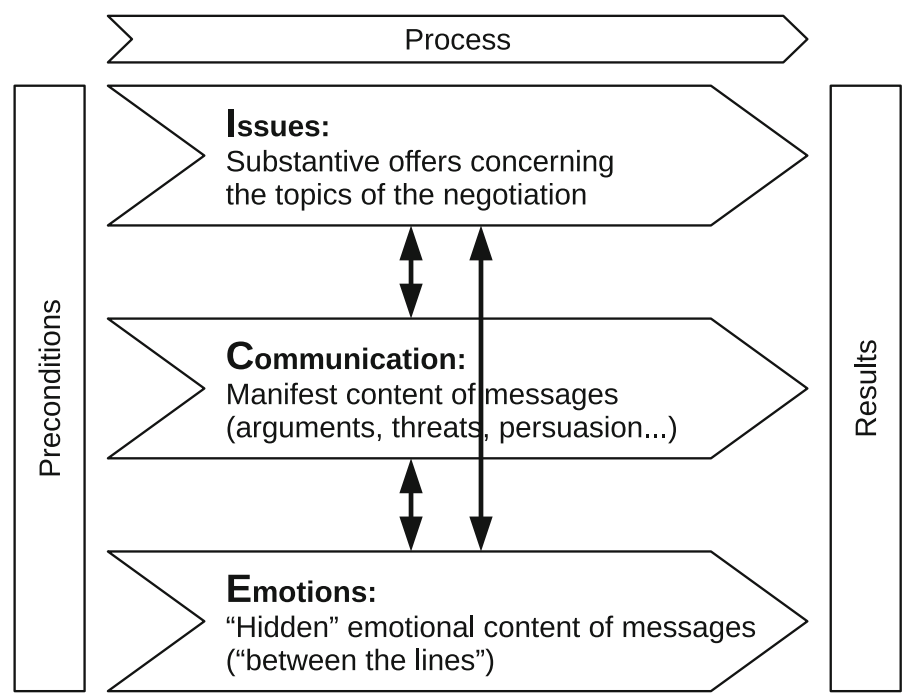

Fig. 1 Issue-communication-emotions (ICE) framework for negotiation processes

dimensions affects outcomes, is an important question for a multidimensional perspective of negotiation research.

We thus focus on the process perspective as a common ground between dimensions. This requires a unified framework for negotiation processes, which maps events in the different dimensions onto a common time scale. This time scale must also be comparable across negotiations for data aggregation and statistical analysis. In the present paper, we apply the standardized interpolated path analysis (SIPA) of Vetschera and Filzmoser (2012) to create such a common time scale. We develop a framework of the different dimensions of negotiation processes and their relationships and illustrate the potential of this framework by an exploratory study using existing data.

The remainder of this paper is structured as follows: Sect. 2 gives a brief overview of the SIPA approach as well as the methods employed to measure the different dimensions of negotiations. In Sect. 3, we review existing literature on possible relationships between the three dimensions and derive hypotheses for our study. In Sect. 4, we present some exemplary results and Sect. 5 evaluates the outcomes of this study and provides directions for future research.

\section{Methods}

We apply the SIPA method (Vetschera and Filzmoser 2012) to create a common representation of negotiation processes in all three dimensions considered. SIPA maps negotiations, in which a variable number of offers and messages are exchanged at varying points in time, onto a common time scale and a common set of measurement points. Each offer or message in a negotiation is considered as one observation of a continuous time process (Balakrishnan and Eliashberg 1995). Linear interpolation 


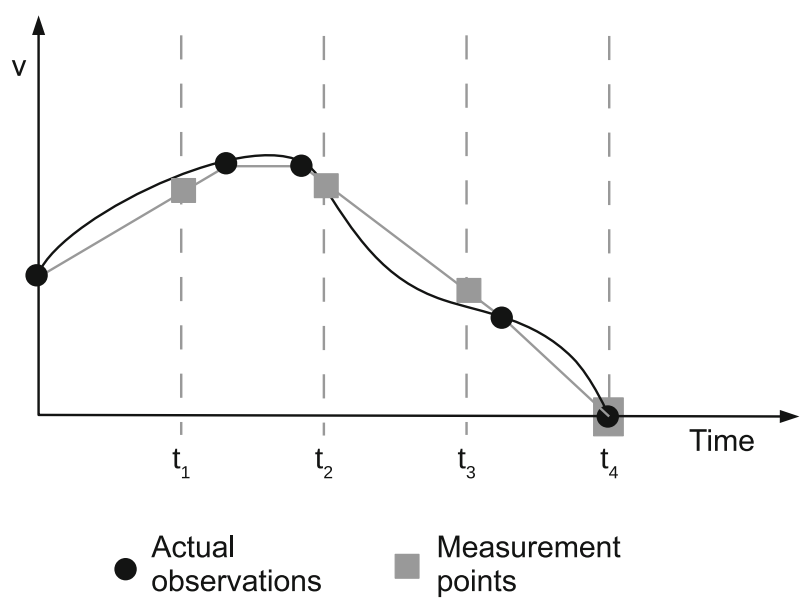

Fig. 2 Illustration of the SIPA method

between observations is used to approximate values at fixed points in time, e.g., each quarter of the negotiation.

The main ideas of SIPA are represented graphically in Fig. 2. We explain the approach for the offer process in terms of utilities, but the same concept can also be applied to the other dimensions. A negotiation consists of several offers $i=1, \ldots N_{n}$, where the total number $N_{n}$ of offers in a negotiation might vary from negotiation to negotiation. The time at which offer $i$ is made is denoted by $s_{i}$. At points in time $s_{i}$ the actual observations of the variables of interest can be made (for example, the utility values of actual offers can be calculated from issue values). For this exposition, we consider only one variable $v$ that is measured for each offer. The approach can of course be applied to any number of variables (like the utilities which an offer provides to both sides of the negotiation etc.), and we use it for different variables in each dimension in the following empirical study. Let $v\left(s_{i}\right)$ be the value of variable $v$ observed in offer $i$ at time $s_{i}$. Furthermore, let $T=\left\{t_{1}, \ldots, t_{n}\right\}$ be a set of fixed points in time, the measurement points. For example, $t_{1}, t_{2}, t_{3}$, and $t_{4}$ could denote the end of each quarter of a negotiation. The value of variable $v$ at time $t_{j}$ is linearly interpolated between the two offers preceding and following time $t_{j}$. We define

$$
i^{-}=\max _{s_{i} \leq t_{j}} i
$$

and

$$
i^{+}=\min _{s_{i} \geq t_{j}} i
$$

Note that $i^{-}=i^{+}$in case that one observation occurs exactly at time $t_{j}$. In Fig. 2, for example, the very last offer also marks the end of the negotiation and thus coincides with the end of the fourth quarter of the negotiation. 
The value $v\left(t_{j}\right)$ at time $t_{j}$ is then calculated by linear interpolation as

$$
v\left(t_{j}\right)=\frac{s_{i^{+}}-t_{j}}{s_{i^{+}}-s_{i^{-}}} v\left(s_{i^{-}}\right)+\frac{t_{j}-s_{i^{-}}}{s_{i^{+}}-s_{i^{-}}} v\left(s_{i^{+}}\right)
$$

The common set of measurement points $t_{j}$ creates a standardized representation of an offer process across negotiations that might contain a varying number of offers, and in which individual offers are made at different points in time. Compared to the more common approach of forming averages across offers contained e.g. in each quarter of a negotiation, SIPA in our view provides several advantages:

- SIPA is independent of the number and temporal distribution of actual observations. For example, in Fig. 2, the third quarter of the negotiation does not contain any actual offer, but still a value can be interpolated for time $t_{3}$.

- Averaging throughout an entire quarter (or some other fraction) of the negotiation might dampen trends and thus the dynamics of the negotiation, which are still discernible in the interpolated path.

- Compared to a discrete event approach, in which the value of the system is assumed to remain constant between observations, an interpolation approach is less sensitive to the actual timing of observations. In a discrete event approach, if an observation is made briefly before a measurement point, the value of that observation is assigned to the measurement point. If the same observation occurred just after the measurement point, the measurement point would still receive the value of the previous observation, which could be drastically different. In contrast, in an interpolation approach, the value assigned to the measurement point is always close to the actual observation made near the measurement point.

For further details on the SIPA method, its advantages and disadvantages, we refer to Vetschera and Filzmoser (2012). The remainder of this section explains how SIPA can be applied to all dimensions of the negotiation process.

On the substantive dimension utilities of offers are of interest. The negotiation support systems (NSS) Negoisst Schoop et al. (2003), used to conduct the experiments of this study, represents utilities in multi-issue negotiations by an additive multi-attribute utility function

$$
u(\mathbf{x})=\sum_{k=1}^{K} w_{k} u_{k}\left(x_{k}\right)
$$

where $u(\mathbf{x})$ is the utility of offer $\mathbf{x}, K$ is the number of issues, $u_{k}($.$) is the partial utility$ function for issue $k$, and $w_{k}$ is the weight representing the importance of the issue to the negotiator.

We denote the negotiators by $A$ and $B$. The utility which an offer proposed by $A$ at time $t_{j}$ provides to $B$ is denoted by $u_{B, A}^{t_{j}}$, and utility of the same offer to $A$ by $u_{A, A}^{t_{j}}$. By combining utility values of both parties we define joint utility (Tripp and Sondak 1992) at time $t_{j}$ as:

$$
J U_{A}^{t_{j}}=u_{A, A}^{t_{j}}+u_{B, A}^{t_{j}}
$$


and utility imbalance, as a measure of fairness, as

$$
U I_{A}^{t_{j}}=\left|u_{A, A}^{t_{j}}-u_{B, A}^{t_{j}}\right|
$$

The content of communication between the negotiators can be transformed into quantitative data by content analysis. A five step approach proposed by Srnka and Koeszegi (2007) was applied. Material sourcing and transcription were automatically performed by the Negoisst system, which stored all exchanged messages. The subsequent steps of unitization, categorization and coding were performed by trained coders.

The category scheme of content categories varies between studies due to different research questions addressed. For the purpose of this study, we applied the broad classification of Olekalns et al. (2003), who categorize content in negotiations according to strategic orientation (distributive or integrative) and strategic function (information or action). This results in four content categories: (i) distributive information, (ii) integrative information, (iii) claiming value, and (iv) creating value, which then were interpolated to quarters of each negotiation using SIPA.

Our measurement of emotions uses entire messages sent by negotiators as units of analysis. In such a setting, a classification of emotions into pre-defined categories is disadvised (Frijda 2009) in favor of less constrained approaches (Cowie and Cornelius 2003). We conceptualize and measure emotions following the dimensional perspective of emotions (Burgoon and Hale 1984), in particular the circumplex model of affect (Russell 1980; Russell and Barrett 1999). The basic assumption of this model is that all emotions and emotion-related states can be described by two underlying bipolar dimensions (Barrett 2004): valence (positive vs. negative emotions), and activation (high vs. low). In contrast to appraisal theories (e.g., Lazarus 2001) interlinking emotions with specific context appraisals, a dimensional model of emotions is not based on a prespecified taxonomy. Put differently, a dimensional perspective of emotions does not primarily seek to distinguish discrete categories, but follows a more holistic approach. Nevertheless, any discrete emotion (e.g., anger) can be defined and identified by its position in relation to the two affective dimensions (Feldman 1995) of valence and activation, as these span a two-dimensional Cartesian space. Consequently, the discrete emotion of anger would fall in between the negative pole of the valence dimension and the high activation pole of the activation dimension. The emotional dimensions of valence and activation are further shown to be highly robust, emerging "whenever individuals label or communicate their own or others' affective experiences" (Barrett and Fossum 2001, p. 334).

To measure these two dimensions of emotions, Multidimensional Scaling (MDS) (Torgerson 1952) was successfully employed in literature (e.g., Barrett 2004; Griessmair and Koeszegi 2009). MDS relies on judgments of similarity or proximity and delivers a spatial representation of the gathered proximity data in an n-dimensional space. The decision of the 'best fitting' number of dimensions is to be based on a goodness-of-fit measure (i.e., Stress) as well as the interpretability of the obtained solution. In the present study this resulted in two dimensions (i.e., valence and activation). The dimensions resulting from MDS are metric variables, which then can be interpolated to quarters of each negotiation using SIPA. 


\section{State-of-the-Art and Hypotheses}

\subsection{Communication and Substantive Dimension}

Economics and game theory often consider communication in joint decision making as cheap talk, which does not directly affect outcomes. However, communication in negotiations can be used to exchange information, threats, etc., which can have a substantive influence on outcomes (Olekalns et al. 1996; Weingart et al. 1999; Olekalns and Smith 2000, 2003; Adair and Brett 2005).

Previous studies indicate that joint gains require sharing information about preferences and priorities, i.e. integrative information exchange (Weingart et al. 1999; Olekalns and Smith 2000, 2003; Adair and Brett 2005). Such information allows value-creating concessions and trade-offs resulting in win-win offers (Hyder et al. 2000; Olekalns and Smith 2003). Value creating and problem solving behavior, which considers the opponent's outcomes (Pruitt 1981; Pruitt and Rubin 1986), also requires such information exchange. This behavior increases joint utility (Hyder et al. 2000) and decreases utility imbalance.

In contrast, positional bargaining (Fisher and Ury 1981), claiming value, defying concessions, and similar behavior increases the risk of inferior results (Olekalns and Smith 2003). Theory and evidence suggest that negotiators who frequently use competitive strategies such as demands or threats fail to reach satisfactory outcomes (Lewis and Fry 1977; Schulz and Pruitt 1978; Putnam and Jones 1982; Donohue et al. 1984; Olekalns and Smith 2000). According to the dual concern model (Pruitt 1981; Pruitt and Rubin 1986), an exclusive focus on self concern will lead to win-lose situations and thus outcomes characterized by inefficiency (Hyder et al. 2000) and unfairness.

We therefore hypothesize for the relation between the communication and the substantive dimension:

H1a An integrative orientation in communication-i.e. providing integrative information and creating value-is positively related to joint utility and negatively to utility imbalance.

H1b A distributive orientation in communication-i.e. distributive information and claiming value - is negatively related to joint utility and positively to utility imbalance.

\subsection{Emotional and Substantive Dimension}

By communicating with each other, the negotiators enact a social context, also giving rise to emotions (Barry and Oliver 1996). Emotions are thus always present in social interactions and might have a constant impact on negotiation behavior and communication. Emotions influence cognitive processes (Lazarus 2001) as well as behaviors (Frijda et al. 1989). Thus, emotions "color" the decision making process (Damasio 1994) and provide meaning regarding a negotiator's own (Schwarz 1990) as well as the opponent's (Kleef 2009) actions. Consequently, emotions are argued to be central to behavior and communication (Morris and Keltner 2000). 
This interrelation can, for example, be explained by Face Theory (Goffman 1967). Attacking face refers to competitive behaviors accompanied by negative emotions, whereas giving face refers to cooperative behaviors accompanied by positive emotions (Brett et al. 2007). Attribution Theory (Weiner 1985) similarly posits that negative emotions are, for example, related to resolute behavior, whereas positive emotions are related to flexibility (Cheshin et al. 2011). Communication and behavior driving the negotiation process consist of multiple layers of meaning transporting different slices of information (Griessmair and Koeszegi 2009), which together comprise the overall "informativeness of a message" (Sokolova and Lapalme 2012, p. 366). Consequently, communication and behavior are not either fact-based or emotional, but both to different extents. Moreover, since emotions, communication, and behavior are interrelated in a complex manner, they constantly influence each other (Barry and Oliver 1996).

Considering the two dimensions of the circumplex model of affect, activation implies commitment (Rogan and Hammer 1995) or readiness for action (Frijda et al. 1989). Thus it is an indicator for the importance of an issue (Marinier et al. 2009). A higher degree of activation implies that negotiators are more engaged in the achievement of a goal (Weiss and Cropanzano 1996). Additionally, activation increases with uncertainty or task difficulty (cf. Klein and Beith 1985). Consequently, higher degrees of activation indicate higher cognitive involvement and more active engagement in the negotiation (Lewis et al. 1984). This is particularly likely if something is at stake, or becomes more pressing and important. Since a low joint utility, or a high utility imbalance require action to resolve differences, it can be expected that such situations co-vary with higher activation.

In the light of negative emotions, negotiators make smaller concessions (Kleef et al. 2004), behave more defensive or distrusting (Morris and Keltner 2000), reject offers more frequently (Pillutla and Murnighan 1996), and reach lower joint gains (Allred et al. 1997). If negotiators attribute negative emotions to unfairness, the result is a tendency to "punish" the opponent (e.g., Moretti and Pellegrino 2010). Hence, emotions are also evaluations of - the fairness of - offers. In a similar vein, positive emotions can be expected to infuse the offer process positively. Research supports this claim with evidence indicating that positive emotions are interrelated with an increase in joint gains (Carnevale and Isen 1986) or concessions (Baron 1990).

For the relation between the emotion and the substantive dimension we, therefore, hypothesize

H2a Activation is negatively related to the joint utility and positively to utility imbalance.

H2b Positive emotions are positively related to the joint utility, whereas negative emotions are positively related to utility imbalance.

\subsection{Communication and Emotion Dimension}

Activation indicates commitment or engagement (Bodtker and Jameson 2001). Hence, activation can be expected to co-vary with competitive or distributive behaviors (Barsade 2002) because more activated emotions are noticed more quickly and eas- 
ily (Maitlis and Ozcelik 2004), and may thus increase when something needs to be resolved. Moreover, studies on language intensity (e.g., Taylor and Donald 2004) indicate that higher degrees of activation are characteristic for emphasizing or addressing specific concerns, as well as threatening, insulting, or apologizing behaviors. Lower degrees of activation occur when addressing many issues in a less focused manner, as well as in information sharing.

With respect to negative emotions, empirical evidence generally shows that anger and competitive, or distributive behaviors are interrelated (Liu 2009; Kleef et al. 2004). Anger can be used to assert one's position, or to signal toughness (Kleef et al. 2004), and was also found to increase risk tolerance (Lerner and Keltner 2001). Moreover, anger and value claiming are positively related (Overbeck et al. 2010). Positive emotions, such as happiness, are generally interlinked with cooperative, or integrative behaviors (Barsade 2002; Carnevale and Isen 1986). For instance, positive emotions coincide with pro-social (Batson et al. 1979), or trusting behaviors (Morris and Keltner 2000). Additionally, positive emotions are positively related to flexibility (Druckman and Broome 1991), or creativity and problem solving behaviors (Isen et al. 1987). In the light of positive emotions, negotiators are also more likely to signal their willingness for cooperation (Kleef et al. 2004).

For the interrelation between the emotion and the communication dimension we, therefore, hypothesize

H3a Activation is positively related to a distributive orientation in communication-i.e. value claiming and distributive information-, and negatively to an integrative orientation in communication-i.e. value creation and integrative information.

H3b Positive emotions are positively related to an integrative orientation in communication - i.e. value creating and integrative information-, whereas negative emotions are positively related to a distributive orientation in communicationi.e. value claiming and distributive information.

\section{Empirical Study}

\subsection{Experiment}

For our analyses, we used data from a previous negotiation experiment conducted with the NSS Negoisst (Schoop et al. 2003). Negoisst is a web-based system that offers decision and communication support to negotiators. Decision support is provided by eliciting an additive multi-attributive utility function and presenting utilities of offers in graphical and tabular form. Communication support is provided by the system at the syntactic, semantic and pragmatic levels. At the syntactic level, specific types of messages can be identified. The exchange of messages follows an alternating negotiation protocol, e.g. a question has to be followed by a clarification or an offer by either a counter-offer or acceptance. The system allows to link the natural language messages to issue values via semantic enrichment. At the pragmatic level, the system 
distinguishes between formal and informal communication. The system records all offers and messages, which build the basis for our analyses.

The experiment was conducted as part of a larger study comparing behavioral and economic negotiation support (Gettinger et al. 2012). A total of 234 students-i.e. 117 dyads - from four European universities participated in this experiment. Participants represented either a Western European or an Eastern European company in bilateral joint venture negotiations. The case contained seven issues with continuous or discrete options. It was thus quite complex and designed to induce a high level of conflict, as it contained only narrow zones of possible agreement. The preferences of the parties were provided in the form of private information about issue weights and reservation levels, as well as utility schemes for each issue. To avoid information spill-overs, all participants from the same university were assigned to the same role.

Participants first received training on the system, then information about demographics, language and negotiation skills was collected via a pre-negotiation questionnaire. After completing the questionnaire, participants had two weeks to complete the negotiations. The case indicated the existence of outside options to explicitly allow negotiations to fail. After the two week period, participants received a post-negotiation questionnaire concerning their satisfaction with the negotiation process and outcome. The experiment was part of the course requirements in international negotiation courses provided at the four participating universities. Subjects were rewarded for participating in the experiment by course credits, independently of the outcomes they reached.

\subsection{Measurement and Descriptive Statistics}

The utility values calculated and stored by Negoisst were directly used for analyses of the substantive dimension. We applied the SIPA method outlined in Sect. 2 to interpolate the utility values of offers from both sides at the end of each quarter of the negotiations. From these values, we calculated joint utility and utility imbalance for both parties, which were then averaged across parties.

Content analysis of the 1489 messages exchanged during the experiment was performed by seven trained coders. The first step performed by the coders was to separate messages into thought units. Reliability of this step was evaluated by Guetzkow's $U$ (Holsti 1969). With values ranging from 0.001 to 0.022 for the seven coder teams and their respective subsets of data, satisfactory consistency was achieved (Simons 1993). Remaining inconsistencies were discussed and resolved by the coders. This resulted in a data set of 24,311 thought units.

The category scheme used for the actual coding of thought units was developed via a deductive-inductive procedure (Srnka and Koeszegi 2007). Starting from Walcott's "Bargaining Process Analysis II" scheme (Putnam and Jones 1982), categories were inductively added or deleted based on the analyzed content. The coders then individually assigned each thought unit to one of the eleven main categories shown in Table 1.

To evaluate the reliability of coding, Cohen's Kappa (Cohen 1960) was calculated. The values obtained were in the range from 0.808 to 0.972 and thus well above the acceptability threshold 0.8 or 0.7 for exploratory studies (Lombard et al. 2002). Finally, coders discussed inconsistencies and agreed on one category for each thought unit. 
Table 1 Main categories of the category scheme and their assignment to the categories of Olekalns et al. (2003)

\begin{tabular}{|c|c|}
\hline Category & Description \\
\hline \multicolumn{2}{|l|}{ Integrative info } \\
\hline Priority information & $\begin{array}{l}\text { Ask or provide information about priorities and aspiration } \\
\text { levels }\end{array}$ \\
\hline \multicolumn{2}{|l|}{ Distributive info } \\
\hline Positional information & $\begin{array}{l}\text { Provision of facts or statements to underline the negotiator's } \\
\text { position and persuade }\end{array}$ \\
\hline \multicolumn{2}{|l|}{ Creating value } \\
\hline Make concession & $\begin{array}{l}\text { Making or offering an unconditional or conditional } \\
\text { (log-rolling) concession }\end{array}$ \\
\hline Social relationship & $\begin{array}{l}\text { statements that constitute empathic communication } \\
\text { (expressing concern, emotions, trust) }\end{array}$ \\
\hline \multicolumn{2}{|l|}{ Claiming value } \\
\hline Positional offer & Positional or bottom-line offers and value claiming \\
\hline Request concession & Requesting concessions from the opponent \\
\hline Negative response & Rejection of proposals and expression of negative emotions \\
\hline Tactics & $\begin{array}{l}\text { Use tactics (pressure, promises, authority), requesting offers } \\
\text { and providing incorrect information }\end{array}$ \\
\hline Substantiate position & $\begin{array}{l}\text { Normative statements referring to fairness, requesting } \\
\text { understanding, etc. }\end{array}$ \\
\hline \multicolumn{2}{|l|}{ Other } \\
\hline Negotiation process & $\begin{array}{l}\text { Communication related to the negotiation process like } \\
\text { address, closing or signature, time planning }\end{array}$ \\
\hline Negotiation system & $\begin{array}{l}\text { Communication concerning the negotiation support system } \\
\text { and its functionalities }\end{array}$ \\
\hline
\end{tabular}

For the purpose of this study, the resulting categories were further aggregated into the four main communication categories of negotiations proposed by Olekalns et al. (2003) as shown in Table 1. Categories referring to the negotiation process and system were not used in the subsequent analysis. We then used the relative share of each of these aggregated categories in each message as a state variable and applied the SIPA approach to interpolate the communication state of each negotiation at the end of each quarter.

To measure the emotional content of messages, we employed a three-step MDSbased procedure. In the first step the input data for the MDS procedure is constructed by assessing the similarity or proximity of the analyzed stimuli (i.e., entire negotiation messages). In particular, we had raters judge entire negotiation messages according to their emotional similarity. To do so we used a minimally constrained free sorting task (e.g., Lawless et al. 1995), which was undertaken by uninvolved-and thus unbiased-students as raters. Specifically, groups of up to 26 raters each judged the same subset of negotiation messages according to their similarity. This proceeded as follows: Raters received work packages including instructions and up to 250 messages printed on single sheets of paper. The raters were instructed to sort these messages into 
decks according to emotional similarity. The number of potential decks was neither pre-specified nor limited. Proximity of two messages was measured by the number of raters who assigned them to the same deck. The resulting proximity matrix was then processed by PERMAP 11.8a (Heady and Lucas 1997). We used nonmetric MDS with Euclidean distances as distance measures, as this approach is preferable when analyzing data based on subjective similarity judgments (Bartholomew et al. 2008). Based on the goodness-of-fit measure (Stress-1) as well as the potential interpretability of dimensions, we identified a two-dimensional solution. Stress-1 for this solution was 0.05. Consequently, we obtained a representation in two-dimensional Cartesian space, which was finally rotated such that the two axes reflect the two dimensions of valence and activation. As such our MDS results are in accord with the circumplex model of affect (Russell 1980; Russell and Barrett 1999), and the emotional dimensions can thus be interpreted concordantly. The two variables (i.e., emotional dimensions) were then also interpolated at the end points of each quarter of the negotiations.

Table 2 summarizes descriptive statistics for the measures of all three dimensions at the end of each quarter of the negotiations.

\subsection{Results}

\subsubsection{Substantive and Communication Dimension}

To test our hypotheses, we used correlation analysis. We consider the negotiation process to consist of three streams, but we do not assume that there is a hierarchy between these streams, or that there exist clear causal relationships between the dimensions. Thus, models assuming a causal relationship between variables would be inadequate. We calculate correlation coefficients between variables across dimensions at the same points in time within the negotiation. We thus focus on the relationship between the dimensions, and not on the dynamics within each dimension.

Hypotheses $\mathrm{H} 1 \mathrm{a}$ and $\mathrm{H} 1 \mathrm{~b}$ referred to the relationship between substantive and communication dimensions. Table 3 shows the correlation coefficients between joint utility and contract imbalance on the one hand, and the usage of the four communication categories on the other hand. These results provide only weak evidence in support of H1. We find a significant, but not strong, positive correlation between value creation and joint utility in the two middle quarters of negotiations, and the expected negative correlation to utility imbalance in the second and fourth quarters. Contrary to expectations, the only significant correlation of integrative information to joint utility is negative. As expected, there is a positive relationship between distributive information and contract imbalance in some quarters, and a negative relationship with integrative information.

Joint utility is an accumulated value resulting from all concessions up to the point at which it is measured. We therefore also calculated the correlation coefficients between value creation within each quarter of the negotiation-i.e. joint utility at the end minus at the beginning of each quarter-and the four communication categories. In that analysis, we found no significant correlations. 
Table 2 Descriptive statistics of all dimensions

\begin{tabular}{lllll}
\hline Progress & $25 \%$ & $50 \%$ & $75 \%$ & $100 \%$ \\
\hline $\begin{array}{l}\text { Substantive measures } \\
\text { Joint utility }\end{array}$ & & & \\
Mean & 1.0568 & 1.0741 & 1.0852 & 1.0572 \\
Median & 1.0507 & 1.0672 & 1.0843 & 1.0500 \\
SD & 0.0534 & 0.0565 & 0.0553 & 0.0595
\end{tabular}

Utility imbalance

$\begin{array}{lllll}\text { Mean } & 0.6915 & 0.5288 & 0.3268 & 0.1540 \\ \text { Median } & 0.7324 & 0.5140 & 0.2855 & 0.1500 \\ \text { SD } & 0.1644 & 0.1944 & 0.1874 & 0.1274\end{array}$

Communication measures

Create value

$\begin{array}{lllll}\text { Mean } & 0.2197 & 0.2250 & 0.2440 & 0.2942 \\ \text { Median } & 0.2230 & 0.2172 & 0.2390 & 0.2801 \\ \text { SD } & 0.0850 & 0.0809 & 0.0989 & 0.1467\end{array}$

Claim value

$\begin{array}{lllll}\text { Mean } & 0.2348 & 0.2550 & 0.2599 & 0.2215 \\ \text { Median } & 0.2336 & 0.2332 & 0.2492 & 0.2000 \\ \text { SD } & 0.0898 & 0.1033 & 0.1097 & 0.1749\end{array}$

Integrative info

$\begin{array}{lllll}\text { Mean } & 0.0527 & 0.0576 & 0.0581 & 0.0359 \\ \text { Median } & 0.0400 & 0.0471 & 0.0504 & 0.0000 \\ \text { SD } & 0.0437 & 0.0512 & 0.0487 & 0.0540\end{array}$

Distributive info

$\begin{array}{lllll}\text { Mean } & 0.1442 & 0.1525 & 0.1176 & 0.0349 \\ \text { Median } & 0.1462 & 0.1599 & 0.1125 & 0.0000 \\ \text { SD } & 0.0800 & 0.0856 & 0.0765 & 0.0558\end{array}$

Emotion measures

Valence

$\begin{array}{lrrrr}\text { Mean } & 0.0717 & -0.0188 & -0.0448 & 0.0528 \\ \text { Median } & 0.1168 & -0.0165 & -0.0360 & 0.0570 \\ \text { SD } & 0.1900 & 0.1757 & 0.2235 & 0.2766\end{array}$

Activation

$\begin{array}{lrrrr}\text { Mean } & -0.0386 & 0.0199 & 0.0389 & -0.0036 \\ \text { Median } & -0.0381 & 0.0048 & 0.0213 & 0.0155 \\ \text { SD } & 0.1129 & 0.1322 & 0.1782 & 0.2099\end{array}$

\subsubsection{Substantive Behavior and Emotions}

Hypotheses $\mathrm{H} 2 \mathrm{a}$ and $\mathrm{H} 2 \mathrm{~b}$ postulated a negative relationship between activation and joint utility, and a positive relationship with contract imbalance, as well as relationships in the opposite directions for valence. As Table 4 shows, there is only scarce evidence 
Table 3 Correlations between substantive behavior and communication

\begin{tabular}{|c|c|c|c|c|c|c|c|c|}
\hline \multirow[t]{2}{*}{ Progress } & \multicolumn{4}{|c|}{ Joint utility } & \multicolumn{4}{|c|}{ Utility imbalance } \\
\hline & $25 \%$ & $50 \%$ & $75 \%$ & $100 \%$ & $25 \%$ & $50 \%$ & $75 \%$ & $100 \%$ \\
\hline Create value & 0.006 & $0.204^{*}$ & $0.249 * *$ & -0.067 & 0.044 & $-0.219^{*}$ & -0.022 & $-0.260 * *$ \\
\hline Claim value & 0.070 & -0.145 & $-0.216^{*}$ & -0.062 & 0.015 & 0.119 & 0.017 & $0.166 \circ$ \\
\hline Integrative info & 0.096 & -0.068 & $-0.230 *$ & 0.079 & -0.044 & 0.018 & 0.136 & $-0.192 *$ \\
\hline Distributive info & 0.069 & 0.003 & 0.033 & 0.022 & -0.118 & -0.046 & $0.287 * *$ & $0.159 \circ$ \\
\hline
\end{tabular}

*** $p<0.1 \%, * * p<1 \%, * p<5 \%, \circ p<10 \%$

Table 4 Correlations between substantive behavior and emotions

\begin{tabular}{|c|c|c|c|c|c|c|c|c|}
\hline \multirow[t]{2}{*}{ Progress } & \multicolumn{4}{|c|}{ Joint utility } & \multicolumn{4}{|c|}{ Utility imbalance } \\
\hline & $25 \%$ & $50 \%$ & $75 \%$ & $100 \%$ & $25 \%$ & $50 \%$ & $75 \%$ & $100 \%$ \\
\hline Valence & -0.215 & 0.027 & $0.321^{*}$ & -0.191 & 0.063 & -0.059 & -0.109 & $-0.236 \circ$ \\
\hline Activation & 0.132 & 0.140 & -0.077 & 0.102 & $-0.238 \circ$ & -0.065 & $0.271 *$ & 0.070 \\
\hline
\end{tabular}

*** $p<0.1 \%$, ** $p<1 \%, * p<5 \%, \circ p<10 \%$

Table 5 Correlations between communication and emotions

\begin{tabular}{|c|c|c|c|c|c|c|c|c|}
\hline \multirow[t]{2}{*}{ Progress } & \multicolumn{4}{|l|}{ Valence } & \multicolumn{4}{|c|}{ Activation } \\
\hline & $25 \%$ & $50 \%$ & $75 \%$ & $100 \%$ & $25 \%$ & $50 \%$ & $75 \%$ & $100 \%$ \\
\hline Create value & $0.567 * * *$ & $0.427 * *$ & $0.672 * * *$ & $0.695 * * *$ & 0.203 & -0.132 & -0.180 & 0.068 \\
\hline Claim value & $-0.442 * * *$ & $-0.620 * * *$ & $-0.553 * * *$ & $-0.463 * * *$ & -0.044 & $0.226 \circ$ & $0.338^{*}$ & $0.330 *$ \\
\hline Integrative info & -0.187 & 0.045 & -0.154 & 0.002 & 0.121 & -0.094 & $0.301 *$ & 0.250 。 \\
\hline Distributive info & $-0.288^{*}$ & 0.065 & -0.098 & $-0.253 \circ$ & 0.074 & 0.169 & 0.110 & 0.095 \\
\hline
\end{tabular}

$* * * p<0.1 \%, * * p<1 \%, * p<5 \%, \circ p<10 \%$

for these relationships. Most coefficients are insignificant, we only find one positive correlation of valance with joint utility, and one of activation with contract imbalance exceeding the $5 \%$ threshold of significance.

\subsubsection{Communication and Emotions}

Table 5 shows the correlation coefficients between communication categories and the two emotional subdimensions. With respect to valence, our results provide strong support for hypothesis $\mathrm{H} 3 \mathrm{~b}$. There is a significant correlation between action-oriented communication and valence in the expected direction: Value creation is strongly related to positive emotions, value claiming to negative emotions. However, this strong connection is only observable for strategic action, information exhibits only weak correlations with valence. For activation, the relationship to strategic action postulated in $\mathrm{H} 3 \mathrm{a}$ is much weaker than for valence, although the significant correlations have the expected sign. Similarly to valence, the relationship to information is even weaker, 
Table 6 Correlations between emotions and own as well as opponent's communication

\begin{tabular}{|c|c|c|c|c|c|c|c|c|}
\hline \multirow[t]{2}{*}{ Progress } & \multicolumn{4}{|l|}{ Valence } & \multicolumn{4}{|c|}{ Activation } \\
\hline & $25 \%$ & $50 \%$ & $75 \%$ & $100 \%$ & $25 \%$ & $50 \%$ & $75 \%$ & $100 \%$ \\
\hline \multicolumn{9}{|c|}{ Own communication } \\
\hline Create value & $0.533 * * *$ & $0.367 * * *$ & $0.569 * * *$ & $0.616 * * *$ & 0.178 & -0.020 & -0.090 & -0.086 \\
\hline Claim value & $-0.339 * * *$ & $-0.480^{* * *}$ & $-0.506 * * *$ & $-0.433 * * *$ & -0.064 & 0.160 & 0.176 & $0.299 * *$ \\
\hline Integrative info & $-0.187 *$ & -0.047 & $-0.201 *$ & -0.039 & -0.015 & 0.002 & $0.245^{* *}$ & 0.089 \\
\hline Distributive info & $-0.258 * *$ & 0.072 & -0.017 & $-0.218^{*}$ & 0.005 & 0.004 & 0.004 & 0.050 \\
\hline \multicolumn{9}{|c|}{ Opponent's communication } \\
\hline Create value & 0.174 & 0.131 & $0.330 * * *$ & $0.212^{*}$ & 0.038 & -0.123 & -0.158 & 0.158 \\
\hline Claim value & $-0.213^{*}$ & $-0.311 * * *$ & $-0.209 *$ & -0.144 & 0.018 & 0.108 & $0.274 * *$ & 0.069 \\
\hline Integrative info & -0.053 & 0.099 & 0.011 & 0.041 & 0.147 & -0.103 & 0.139 & 0.163 \\
\hline Distributive info & -0.135 & 0.013 & -0.113 & -0.084 & 0.081 & $0.201^{*}$ & 0.146 & 0.052 \\
\hline
\end{tabular}

$* * * p<0.1 \%, * * p<1 \%, * p<5 \%$

and here the significant correlations contradict the direction expected in $\mathrm{H} 3 \mathrm{a}$, we find a positive relationship between integrative information and activation.

Correlation does not imply a causal relationship. Causal relationships between emotions and communication could work in both directions: Receiving communication which claims value could lead to negative emotions, and negotiators expressing negative emotions could be more likely to claim value. To disentangle these effects, we calculated the correlations between the emotions of one party, and the communication behavior of the same party as well as the opponent as shown in Table 6. While effects are significant for both parties, the correlation is stronger within the same party than with the opponent's communication. This makes an influence of emotions on communication more plausible than vice versa.

\section{Discussion and Conclusions}

In the present paper, we have studied the relationships of different dimensions of negotiation processes. Our hypotheses predicted consistent patterns across the three dimensions: According to $\mathrm{H} 3 \mathrm{a}$, lower activation and positive emotions are related to an integrative orientation in communication - integrative information and creating value. At the substantive level, they are accompanied by offers which provide higher joint utility and lower utility imbalance- $-\mathrm{H} 1 \mathrm{a}$ and $\mathrm{H} 2 \mathrm{a}$. In contrast, we expected activation and negative emotions to be related to a distributive orientation in communication$\mathrm{H} 3 \mathrm{~b}-$, lower joint utility and higher imbalance- $-\mathrm{H} 1 \mathrm{~b}$ and $\mathrm{H} 2 \mathrm{~b}$.

Concerning H1, we found only weak evidence for the postulated effects of value creating behavior, which did not occur consistently throughout the negotiations. The relationships between other communication categories and the substantive dimensions were even weaker, and mostly could not be confirmed at all. Thus our results provide only weak support for $\mathrm{H} 1$. 
Results concerning $\mathrm{H} 2$ about the relationships between emotion and substantive behavior also could not support our hypothesis. There were only few weakly significant correlation coefficients, thus we find no evidence for a close relationship between emotions and substantive behavior in negotiations.

In contrast to these negative results concerning $\mathrm{H} 1$ and $\mathrm{H} 2$, results for $\mathrm{H} 3$ provide support for the hypothesis linking emotions and communication behavior. In particular, we find strong evidence for the relation of valence and the strategic action dimension of communication-i.e. creating and claiming value. For the remainder of H3, we find weak support in our results.

The relation between emotions and strategic action confirms literature showing that emotions communicate "social intentions, desired courses of actions, and role-related expectations and behaviors" (Morris and Keltner 2000, p. 13). Emotions put other communication into context by serving as additional positive or negative signals. A study by Oetzel et al. (2000) showed that emotional expressions form part of mutual integrating as well as self-centered dominating behaviors. Investigating online disputes, Brett et al. (2007) showed that acts of attacking face are accompanied by negative emotions and commands, and acts of giving face are connected to positive emotions. Other findings indicate that resoluteness is associated with expressions of anger (e.g., Kopelman et al. 2006), or that cooperative behaviors are associated with expressions of happiness (e.g., Stouten and Cremer 2010). Utilizing a computer-mediated negotiation simulation, Pietroni et al. (2008) further found an interrelation between positive emotions and the reduction of fixed-pie perceptions, that is, an increase in integrative behaviors - and the inverse effect for negative emotions-, in particular when an issue was of high importance to a negotiator. Our results add to this research in finding that communication is enriched or supported by emotional expressions: Emotions can help to highlight the strategic action dimension of communication and, consequently, make it more salient. Additionally, the co-variation of positive emotions and value-creation, as well as of negative emotions and value-claiming, implies that negotiators adopt emotionally congruent communications (cf. Forgas 1998).

Summarizing the results with respect to our three hypotheses, we thus have to conclude that substantive behavior on the one hand, and communication and emotions on the other hand, seem to form quite distinct parts of the negotiation process. At least the results of this study do not indicate the presence of strong relationships between them.

However, we think it would be misleading to conclude from this result that communication in negotiations and emotions are "cheap talk", which has no impact on the "real" outcome of the negotiation. There are still significant differences between successful and failed negotiations in the communication and emotional dimensions. Ignoring these dimensions thus would mean ignoring the risk that negotiations could not reach an agreement at all.

In discussing the implications of our results, one also has to be aware of the limitations of our study. It is based on a student sample, which raises some questions of generalizability. Furthermore, we only used one case, which was quite complex and was specifically designed to induce a rather high level of conflict. Thus, the relationships between dimensions in more integrative negotiations might be different. Furthermore, our analysis is based on negotiations conducted via a specific NSS. 
Although the study on which our data is based (Gettinger et al. 2012) utilized different treatments in which different features of the system were enabled or disabled, the overall characteristics of the system still remained constant and might have influenced behavior.

Thus, our present analysis is only a first step toward exploring the relationships of the different dimensions of negotiation processes in wider contexts. Future research should also apply multivariate techniques to analyze the relationships and interactions between the dimensions of the negotiation process simultaneously. The SIPA method proved to provide a useful framework to establish a common process representation not only across different negotiations of a study but also across dimensions. More elaborate analysis methods can then be used to provide a clearer picture of negotiation processes. In particular, consistency between the substantive, the communication and the emotional dimensions could be another important factor leading to success or failure of negotiations and deserves consideration in future research.

Acknowledgments Open access funding provided by University of Vienna.

Open Access This article is distributed under the terms of the Creative Commons Attribution 4.0 International License (http://creativecommons.org/licenses/by/4.0/), which permits unrestricted use, distribution, and reproduction in any medium, provided you give appropriate credit to the original author(s) and the source, provide a link to the Creative Commons license, and indicate if changes were made.

\section{References}

Adair WL, Brett JM (2005) The negotiation dance: time, culture, and behavioral sequences in negotiation. Organ Sci 16(1):33-51

Allred KG, Mallozzi JS, Matsui F, Raia CP (1997) The influence of anger and compassion on negotiation performance. Organ Behav Hum Decis Process 70(3):175-187

Balakrishnan PV, Eliashberg J (1995) An analytical process model of two-party negotiations. Manage Sci 41(2):226-243

Baron RA (1990) Environmentally induced positive affect: its impact on self-efficacy, task performance, negotiation, and conflict. J Appl Soc Psychol 20(5):368-384

Barrett LF (2004) Feelings or words? Understanding the content in self-report ratings of experienced emotion. J Pers Soc Psychol 87(2):266-281

Barrett LF, Fossum T (2001) Mental representations of affect knowledge. Cogn Emot 15(3):333-363

Barry B, Oliver RL (1996) Affect in dyadic negotiation: a model and propositions. Organ Behav Hum Decis Process 67(2):127-143

Barsade SG (2002) The ripple effect: emotional contagion and its influence on group behavior. Adm Sci Q 47(4):644-675

Bartholomew DJ, Steele F, Galbraith J, Moustaki I (2008) Analysis of multivariate social science data. CRC Press, London

Batson DC, Coke JS, Chard F, Smith D, Taliaferro A (1979) Generality of the glow of goodwill: Effects of mood on helping and information acquisition. Soc Psychol Q 42(2):176-179

Bazerman MH, Curhan JR, Moore DA, Valley KL (2000) Negotiation. Annu Rev Psychol 51:279-314

Bodtker AM, Jameson JK (2001) Emotion in conflict formation and its transformation: application to organizational conflict management. Int J Confl Manag 12(3):259-275

Brett JM, Olekalns M, Friedman R, Goates N, Anderson C, Lisco CC (2007) Sticks and stones: language, face, and online dispute resolution. Acad Manag J 50(1):85-99

Burgoon JK, Hale JI (1984) The fundamental topoi of relational communication. Commun Monogr 51:193214 
Butt AN, Choi JN, Jaeger AM (2005) The effects of self-emotion, counterpart emotion, and counterpart behavior on negotiator behavior: a comparison of individual-level and dyad-level dynamics. J Organ Behav 26:681-704

Carnevale PJ, Pruitt DG (1992) Negotiation and mediation. Annu Rev Psychol 43:531-582

Carnevale PJD, Isen AM (1986) The influence of positive affect and visual access on the discovery of integrative solutions in bilateral negotiation. Organ Behav Hum Decis Process 37(1):1-13

Cheshin A, Rafaeli A, Bos N (2011) Anger and happiness in virtual teams: emotional influences of text and behavior on others' affect in the absence of non-verbal cues. Organ Behav Hum Decis Process 116(1):2-16

Cohen J (1960) A coefficient of agreement for nominal scales. Educ Psychol Measurement 20:37-46

Cowie R, Cornelius RR (2003) Describing the emotional states that are expressed in speech. Speech Commun 40(1-2):5-32

Damasio A (1994) Descartes' error: emotions, reason, and the human brain. Avon Books, New York

Donohue WA, Diez ME, Hamilton M (1984) Coding naturalistic negotiation interaction. Human Commun Res 10:403-425

Druckman D, Broome BJ (1991) Value differences and conflict resolution: Familiarity or liking? J Confl Resolut 35(4):571-593

Feldman LA (1995) Valence focus and arousal focus: individual differences in the structure of affective experience. J Pers Soc Psychol 69(1):153-166

Filzmoser M, Hippmann P, Vetschera R (2014) Multidimensional analysis of negotiation processes. In: Zaraté P, Camilleri G, Kamissoko D, Amblard F (eds) Proceedings of the joint international conference of the INFORMS GDN section and the EURO Working Group on DSS, Toulouse, pp 8-15

Fisher R, Ury W (1981) Getting to yes. Houghton-Mifflin, Boston

Forgas JP (1998) On feeling good and getting your way: mood effects on negotiator cognition and bargaining strategies. J Pers Soc Psychol 74(3):565-577

Frijda NH (2009) Emotions, individual differences and time course: reflections. Cogn Emot 23(7):14441461

Frijda NH, Kuipers P, Ter Schure E (1989) Relations among emotion, appraisal, and emotional action readiness. J Pers Soc Psychol 57(2):212-228

Gettinger JR, Dannenmann A, Druckman D, Filzmoser M, Mitterhofer R, Reiser A, Schoop M, Vetschera R, van der Wijst P, Koeszegi ST (2012) Impact of and interaction between behavioral and economic decision support in electronic negotiations. In: Hernández JE, Zaraté P, Dargam F, Delibašić B, Liu S, Ribeiro R (eds) Collaboration in real environments, Lecture Notes in Business Information Processing, vol 121, Springer, Berlin, pp 151-165

Goffman E (1967) Interaction ritual: essays in face-to-face behavior. Aldine Pub. Co., Chicago

Griessmair M, Koeszegi ST (2009) Exploring the cognitive-emotional fugue in electronic negotiations. Group Decis Negot 18(3):213-234

Heady RB, Lucas JL (1997) Permap: an interactive program for making perceptual maps. Behav Res Methods Instrum Comput 29(3):450-455

Holmes ME (1992) Phase structures in negotiation. In: Putnam LL, Roloff ME (eds) Communication and negotiation, Sage, Newbury Park,pp 83-105

Holsti OR (1969) Content analysis for the social sciences and humanities. Addison-Wesley, Reading

Hyder EB, Prietula MJ, Weingart LR (2000) Getting to best: efficiency versus optimality in negotiation. Cogn Sci 24(2):169-204

Isen AM, Daubman KA, Nowicki GP (1987) Positive affect facilitates creative problem solving. J Pers Soc Psychol 52(6):1122-1131

Klein K, Beith B (1985) Re-examination of residual arousal as an explanation of aftereffects: Frustration tolerance versus response speed. J Appl Psychol 70(4):642-650

Koeszegi ST, Vetschera R (2010) Analysis of negotiation processes. In: Kilgour DM, Eden C (eds) Handbook of group decision and negotiation. Springer, Dordrecht, pp 121-137

Kopelman S, Rosette AS, Thompson LL (2006) The three faces of Eve: strategic displays of positive, negative, and neutral emotions in negotiations. Organ Behav Hum Decis Process 99(1):81-101

Lawless HT, Sheng N, Knoops SSCP (1995) Multidimensional scaling of sorting data applied to cheese perception. Food Qual Prefer 6(2):91-98

Lazarus RS (2001) Relational meaning and discrete emotions. In: Scherer KR, Schorr A, Johnstone T (eds) Appraisal processes in emotion: series in affective science. Oxford University Press, New York, pp 37-67 
Lerner JS, Keltner D (2001) Fear, anger, and risk. J Pers Soc Psychol 81(1):146-159

Lewis M, Sullivan MW, Michalson L (1984) The cognitive-emotional fugue. In: Izard CE, Kagen J, Zajonc RB (eds) Emotions, cognition, and behavior. University Press, New York and Cambridge, pp 264-288

Lewis SA, Fry WR (1977) Effects of visual access and orientation on the discovery of integrative bargaining alternatives. Organ Behav Human Perform 20:75-92

Liu M (2009) The intrapersonal and interpersonal effects of anger on negotiation strategies: a cross-cultural investigation. Human Commun Res 35(1):148-169

Lombard M, Snyder-Duch J, Bracken CC (2002) Content analysis in mass communication: assessment of reporting of intercoder reliability. Human Commun Res 28:587-604

Maitlis S, Ozcelik H (2004) Toxic decision processes: a study of emotion and organizational decision making. Organ Sci 15(4):375-393

Marinier RP, Laird JE, Lewis RL (2009) A computational unification of cognitive behavior and emotion. Cogn Syst Res 10:48-69

Moretti L, Di Pellegrino G (2010) Disgust selectively modulates reciprocal fairness in economic interactions. Emotion 10(2):169-180

Morris MW, Keltner D (2000) How emotions work: the social functions of emotional expression in negotiations. Res Organ Behav 22:1-50

Oetzel JG, Ting-Toomey S, Yokochi Y, Masumoto T, Takai J (2000) A typology of facework behaviors in conflicts with best friends and relative strangers. Commun Q 48(4):397-419

Olekalns M, Smith PL (2000) Understanding optimal outcomes: the role of stategy in competitive negotiations. Hum Commun Res 26(4):527-557

Olekalns M, Smith PL (2003) Social motives in negotiation: the relationship between dyad composition, negotiation processes and outcomes. Int J Confl Manag 14(3/4):233-254

Olekalns M, Smith PL, Walsh T (1996) The process of negotiating: strategy and timing as predictors of outcomes. Organ Behav Hum Decis Process 68(1):68-77

Olekalns M, Brett JM, Weingart LR (2003) Phases, transitions and interruptions: modeling processes in multi-party negotiations. Int J Confl Manag 14(3/4):191-211

Overbeck JR, Neale MA, Govan CL (2010) I feel, therefore you act: intrapersonal and interpersonal effects of emotion on negotiation as a function of social power. Organ Behav Hum Decis Process 112(2):126139

Pietroni D, Van Kleef GA, De Dreu CKW, Pagliaro S (2008) Emotions as strategic information: effects of other's emotional expressions on fixed-pie perception, demands, and integrative behavior in negotiation. J Exp Soc Psychol 44(6):1444-1454

Pillutla MM, Murnighan JK (1996) Unfairness, anger, and spite: emotional rejections of ultimatum offers. Organ Behav Hum Decis Process 68(3):208-224

Pruitt DG (1981) Negotiation behavior. Academic Press, New York

Pruitt DG, Rubin JZ (1986) Social conflict: escalation, stalemate, and settlement. Random House, New York

Putnam LL, Jones TS (1982) The role of communication in bargaining. Commun Monogr 49:262-282

Raiffa H (1982) The art and science of negotiation. Belknap, Cambridge

Rogan RG, Hammer MR (1995) Assessing message affect in crisis negotiations: an exploratory study. Hum Commun Res 21(4):553-574

Russell JA (1980) A circumplex model of affect. J Pers Soc Psychol 39(6):1161-1178

Russell JA, Barrett LF (1999) Core affect, prototypical emotional episodes, and other things called emotion: dissecting the elephant. J Pers Soc Psychol 76(5):805-819

Schoop M, Jertila A, List T (2003) Negoisst: a negotiation support system for electronic business-to-business negotiations in e-commerce. Data Knowl Eng 47(3):371-401

Schulz JW, Pruitt DG (1978) The effects of mutual concern on joint welfare. J Exp Soc Psychol 14:480-492

Schwarz NN (1990) Feelings as information: Informational and motivational functions of affective states. In: Higgins ET, Sorrentino RM (eds) Handbook of motivation and cognition: Foundations of social behavior, Vol. 2, Guilford Press, New York, pp 527-561

Sebenius JK (1992) Negotiation analysis: a characterization and review. Manage Sci 38(1):18-38

Simons T (1993) Speech patterns and the concept of utility in cognitive maps: the case of integrative bargaining. Acad Manag J 36:139-156

Sokolova M, Lapalme G (2012) How much do we say? Using informativeness of negotiation text records for early prediction of negotiation outcomes. Group Decis Negot 21(3):363-379 
Srnka KJ, Koeszegi ST (2007) From words to numbers: how to transform rich qualitative data into meaningful quantative results: guidelines and exemplary study. Schmalenbach's Bus Rev 59:29-57

Stouten J, De Cremer D (2010) "Seeing is believing": the effects of facial expressions of emotion and verbal communication in social dilemmas. J Behav Decis Mak 23(3):271-287

Taylor PJ, Donald I (2004) The structure of communication behavior in simulated and actual crisis negotiations. Human Commun Res 30(4):443-478

Torgerson WS (1952) Multidimensional scaling: I. theory and method. Psychometrika 17(4):401-419

Tripp TM, Sondak H (1992) An evaluation of dependent variables in experimental negotiation studies: impasse rates and Pareto efficiency. Organ Behav Hum Decis Process 51(2):273-295

Van Kleef GA (2009) How emotions regulate social life: the emotions as social information (EASI) model. Curr Dir Psychol Sci 18(3):184-188

Van Kleef GA, De Dreu CKW, Manstead ASR (2004) The interpersonal effects of anger and happiness in negotiations. J Pers Soc Psychol 86(1):57-76

Vetschera R (2013) Negotiation processes: an integrated perspective. EURO J Decis Process 1(1-2):135164

Vetschera R, Filzmoser M (2012) Standardized interpolated path analysis of offer processes in enegotiations. In: Kauffman RJ (ed) International conference on electronic commerce ICEC 2012, Singapore, pp 134-140

Weiner B (1985) An attributional theory of achievement motivation and emotion. Psychol Rev 92(4):548573

Weingart LR, Prietula MJ, Hyder EB, Genovese CR (1999) Knowledge and the sequential process of negotiation: a Markov chain analysis of response-in-kind. J Exp Soc Psychol 35(4):366-393

Weiss HM, Cropanzano R (1996) Affective events theory: A theoretical discussion of the structure, causes and consequences of affective experiences at work. In: Staw BM, Cummings LL (eds) Research in organizational behavior, vol 18, JAI Press, Greenwich, CT, pp 1-74 